Elemental composition of human tissues and body fluids. Weinheim: Verlag Chemi, 1978: 38.

4 Henkin R I, Patten B M, Re P K, Bronzer D A. A syndrome of acute zinc loss. Arch Neurol 1975; 32: 745-51.

5 Shaw J C L. Trace elements in the fetus and young infant. Am J Dis Child 1979; 133: 1260-8.

6 Picciano M F, Guthrie H A. Copper, iron, and zinc contents of mature human milk. Am J Clin Nutr 1976; 29: $242-54$.
7 Aggett P J, Harries J T. Current status of zinc in health and disease states. Arch Dis Child 1979; 54: 909-17.

Correspondence to Dr H J Goldberg, Mercy Maternity Hospital, Clarendon Street, East Melbourne, Victoria 3002, Australia.

Received 22 March 1982

\title{
Renal pseudotumours caused by xanthogranulomatous pyelonephritis
}

\author{
A R WATSON, H B MARSDEN, M LENDON, AND P H MORRIS JONES \\ Royal Manchester Children's Hospital, and Booth Hall Children's Hospital, Manchester
}

SUMMARY Five cases of xanthogranulomatous pyelonephritis are described. Wilms's tumour was suspected preoperatively in 2 of the cases and a renal tumour appeared to be confirmed at laparotomy in three. Patho ogical examination is diagnostic and the condition appears to be always unilateral. Nephrectomy is curative.

Xanthogranulomatous pyelonephritis (XPN) is a rare outcome of bacterial infection of the kidney, characterised by unilateral destruction of renal parenchyma and the accumulation of lipid-laden foamy macrophages either surrounding abscess cavities or as discrete yellow nodules. Most cases have been described in women, generally they have a non-functioning kidney, urolithiasis, and urinary infection especially with Proteus species. The similarity of XPN to renal cell carcinoma has often been noted and the condition may also mimic perinephric abscess, pyelonephritis with stones, renal carbuncle, and tuberculosis. ${ }^{1}$

Some 45 cases of XPN have been documented since the first description in $1963 .^{2-6}$ We describe 5 more cases in order to stress the importance of considering XPN in the differential diagnosis of renal tumours.

\section{Patients}

Case 1. A 2-year-old boy was noticed at routine examination to be anaemic with weight below the 3rd centile and height on the 10th centile. A leftsided abdominal mass was palpable and an intravenous urogram (IVU) showed patchy calcification in the lower portion of the left kidney with irregular distortion and enlargement of the upper calyces. His haemoglobin concentration was 6.8 $\mathrm{g} / \mathrm{dl}$ with a white cell count of $13.8 \times 10^{9} / 1,72 \%$ neutrophils. Urine analysis showed pyuria but no growth on culture.

After blood transfusion laparotomy was performed for a suspected Wilms's tumour. This appeared to be confirmed at the time of operation with enlarged glands in the para-aortic and inferior mesenteric areas. Left nephrectomy and extensive lymph node dissection was performed. Vincristine $0.7 \mathrm{mg}$ was given intravenously at the end of the operation.

Histological examination of the nephrectomy specimen showed changes typical of XPN with abscesses, lipid-filled histiocytes, and chronic inflammatory cells. Proteus sp. were obtained on culture of the pus. The lymph nodes showed reactive hyperplasia. He remains well and free of urinary infection 4 years later with a weight on the 25th centile and height on the 10th centile.

Case 2. A $3 \frac{1}{2}$-year-old boy was admitted for investigation of small stature, anaemia, and poor appetite. His weight was below the 3rd centile and his height between the 3rd and 10th centiles. Abdominal examination showed a palpable right kidney. His haemoglobin concentration was 8.5 $\mathrm{g} / \mathrm{dl}$ with a white cell count of $19.8 \times 10^{9} / 1$. Urine analysis showed pyuria with no growth on culture. Calcification was noted in the right renal area on plain abdominal $x$-ray film and an IVU showed deformity of the right calyceal system in a kidney which was enlarged. Cystoscopy and cystogram showed no ureteric reflux. Operation for suspected pyelonephritis with stones was carried out. A large tumour mass was found which was adherent to the colon, duodenum, liver, and diaphragm with enlarged adjacent lymph nodes. Nephrectomy was performed and he was given vincristine $0.75 \mathrm{mg}$ intravenously in theatre. Pathological examination 
showed XPN and Proteus sp. were cultured from the renal abscesses. The patient remains well 5 years later.

Case 3. A $2 \frac{1}{2}$-year-old boy presented with a 6 months' history of urethral discharge and dysuria. His height and weight were just below the 3rd centile. The haemoglobin concentration was $9.5 \mathrm{~g} / \mathrm{dl}$ with a white cell count of $13 \times 10^{9} / 1$. Urine analysis showed pyuria with a pure growth of Proteus sp.

A poorly functioning left kidney with a bladder calculus were noted on the IVU. Cystolithotomy was performed and an operative cystogram showed bilateral vesicoureteric reflux. A follow-up IVU 9 months later showed a non-functioning left kidney which on a retrograde pyelogram showed a spaceoccupying lesion distorting the upper and middle calyces. Left nephrectomy was performed and pathological examination showed XPN with numerous abscesses. He remains well 3 years later.

Case 4. A 3-year-old boy presented with anorexia and lethargy since having measles 3 weeks previously. He was pale with a palpable mass filling the right side of the abdomen. His height was on the 25th centile with a weight between the 50 and 75th centiles. Haemoglobin concentration was $5.8 \mathrm{~g} / \mathrm{dl}$ with a white cell count of $14.3 \times 10^{9} / 1$. Urine analysis showed excess white cells and no growth in culture. An IVU showed a non-functioning right kidney which on ultrasound showed multiple internal echoes. Right nephrectomy for suspected Wilms's tumour was performed and a huge lobulated renal mass ( $384 \mathrm{~g}$ compared with an expected weight of $48 \mathrm{~g}$ ) was removed. The cut surface showed multiple abscess cavities (Figure) and histological appearances were characteristic of XPN. The mesenteric lymph nodes were enlarged. Proteus vulgaris was cultured from the kidney.

The patient remains well 10 months later.

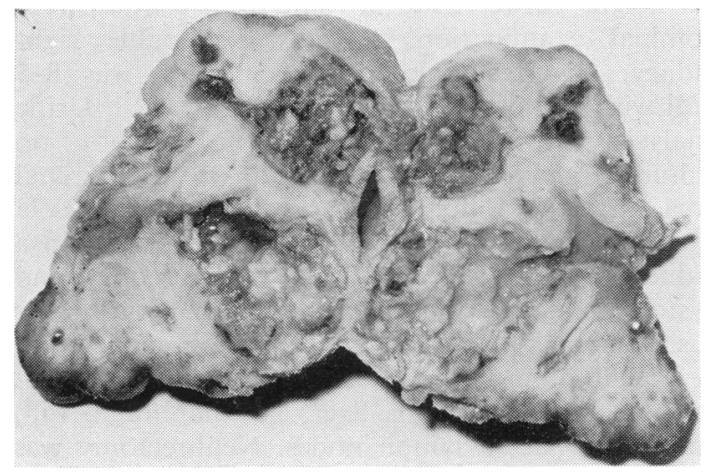

Figure Cut surface of nephrectomy specimen showing multiple abscess cavities.
Case 5. A 12-year-old girl presented with one month's history of abdominal pain and anaemia. She had a palpable non-tender left renal mass. Her haemoglobin level was $11 \mathrm{~g} / \mathrm{dl}$ (on iron treatment) with a white cell count of $12.1 \times 10^{9} / 1$ and an ESR $110 \mathrm{~mm}$ in 1 hour. Her urine specimen was sterile on culture.

An IVU suggested left-sided hydronephrosis perhaps with pelvi-ureteric obstruction. Laparotomy was performed and an enlarged kidney attached to the psoas muscle with fleshy para-aortic lymph nodes was found. A left nephrectomy and lymph node dissection was performed. The initial histological interpretation was that of renal carcinoma of the sarcomatoid variety or a mesoblastic tumour; subsequent histological review suggested the diagnosis of XPN. The girl remains well and symptom free 8 years later.

\section{Discussion}

The 50 reported cases in childhood (including these) show that XPN affects boys and girls equally and there is no predilection for one particular kidney. The condition is almost entirely unilateral with a non-functioning kidney on IVU being found in $72 \%$ and calcification in the renal area in $52 \%$ of cases.

The disease has been discussed elsewhere. ${ }^{7}$ The pathogenesis of the lipid accumulation is unknown but may be associated with venous occlusion and haemorrhage, perhaps with infection and urinary tract obstruction. In $75 \%$ of cases, bacteria have been cultured from the urine or renal abscess cavities with Proteus sp. (particularly P. vulgaris) accounting for $60 \%$ of the isolates.

Two of our 5 patients were suspected of having a Wilms's tumour preoperatively. The clinical suspicion appeared to be confirmed in Case 1 and intravenous vincristine was administered at the time of operation. The drug was also administered in Case 2 because the gross appearances and widespread lymph node enlargement at the time of operation suggested Wilms's tumour. The laparotomy findings suggested Wilms's tumour in Case 4 also, but the cut surface appearance of the nephrectomy specimen strongly suggested XPN to the surgeon who had encountered a similar case. The surgeon who operated on Case 5 was convinced it was a malignant tumour invading the psoas muscle. Fortunately treatment was delayed while a further opinion was sought.

Most children with XPN present with symptoms suggesting non-specific chronic infection-such as failure to thrive, pallor, and lethargy. Recurrent fever was noted in half the reported cases but there is little 
evidence to suggest that these children had received ineffective antibiotic therapy for urinary tract infections. Fever is not uncommon in association with Wilms's tumour with most patients having a palpable abdominal mass compared with only $30 \%$ of XPN cases. The radiological findings in Wilms's tumour are usually those of calyceal distortion on the IVU with calcification being present in only $5-15 \%$ of cases. A solid echo-free mass on ultrasonic examination also suggests tumour but when multiple internal echoes are obtained, which is the usual finding in XPN, it is not possible to be certain that one is not dealing with a Wilms's tumour that has undergone cystic degeneration.

In these 50 cases of XPN the age range was 5 months to 15 years with a mean age at detection of 4.6 years. This figure approximates to that for Wilms's tumour but most cases occur before age 5 years.

Therefore it is important to consider XPN in order to avoid needless preoperative irradiation of a large abdominal mass, extensive lymph node dissection, or administration of myelosuppressive agents at the time of operation. The IVU and renal angiography show no specific features in XPN and the incidence of vesicoureteric reflux on micturating cystourethrography has been poorly documented. It remains to be seen whether the more frequent use of ultrasound examination in combination with the IVU can more accurately predict XPN. ${ }^{3}$

Nephrectomy is curative but in those cases where there is polar involvement $(24 \%$ of cases, $75 \%$ of which are in girls) a partial nephrectomy may suffice. No recurrence of XPN in the contralateral kidney has yet been reported.

We thank Dr A Kennedy, Mr A Jolleys, and Mr $\mathrm{J}$ Cohen for providing clinical details.

\section{References}

1 Malek R S, Greene L F, DeWeerd J H, Farrow G M. Xanthogranulomatous pyelonephritis. Br J Urol 1972; 44: 296-308.

2 Avnet N L, Roberts T W, Goldberg H R. Tumefactive xanthogranulomatous pyelonephritis. $A J R$ 1963; 90: 89-96.

${ }^{3}$ Fahr K, Oppermann H C, Schärer K, Greinacher I. Xanthogranulomatous pyelonephritis in childhood. Pediatr Radiol 1979;8: 10-6.

4 Harzmann R, Bichler K-H, Schmitz-Moormann P, Erdmann D. Xanthogranulomatöse pyelonephritis. Actuelle Urology 1977; 8: 319-25.

5 Bagley F H, Stewart A M, Jones P F. Diffuse xanthogranulomatous pyelonephritis in children. An unrecognised variant. J Urol 1977; 118: 434-5.

6 Izzidien A Y, Al-Dewachi H, Al-Hasso T K, Abdul Majeed A M. Xanthogranulomatous pyelonephritis in childhood. J Pediatr Surg 1980; 15: 686-9.

7 McDonald G S A. Xanthogranulomatous pyelonephritis. J Pathol 1981 ; 133: 203-13.

Correspondence to $\operatorname{Dr}$ A R Watson, Royal Manchester Children's Hospital, Pendlebury, Manchester M27 1HA.

Received 3 March 1982

\title{
British Paediatric Association
}

\author{
Annual meetings \\ 1983 12-16 April York University \\ 1984 10-14 April York University \\ 1985 16-20 April York University \\ 1986 15-19 April York University
}

